\title{
Prevalence and socioeconomic correlates of autism among children attending primary and secondary schools in south east Nigeria
}

\author{
Josephat M. Chinawa ${ }^{1}$, Pius C. Manyike ${ }^{2}$, Elias C. Aniwada, Awoere T. Chinawa ${ }^{3}$, Herbert A.Obu, \\ Odutola I. Odetunde ${ }^{6}$, Ada R.C. Nwokocha ${ }^{7}$, Roland R. Ibekwe ${ }^{8}$
}

1. College of Medicine, Department of pediatrics, University of Nigeria/ University of Nigeria Teaching Hospital (UNTH), Ituku- Ozalla, Enugu State, Nigeria.

2. Federal Teaching Hospital

3. (Epid\& Med Stat), FWACP, FMCPH Lecturer, College of Community medicine, University of Nigeria/ University of Nigeria Teaching Hospital (UNTH), Ituku- Ozalla, Enugu State, Nigeria.

4. Chinawa Awoere Tamunosiki (MBBS, FMCPH) Consultant community Physician Enugu state University Teaching Hospital Enugu State, Nigeria.

5. Department of Paediatrics, University of Nigeria/ University of Nigeria Teaching Hospital (UNTH), Ituku- Ozalla, Enugu State, Nigeria.

6. College of Medicine,Department of pediatrics, University of Nigeria/ University of Nigeria Teaching Hospital (UNTH), Ituku- Ozalla, Enugu State, Nigeria.

7. College of Medicine, Department of pediatrics, University of Nigeria/ University of Nigeria Teaching Hospital (UNTH), Ituku- Ozalla, Enugu State, Nigeria.

8. Department of pediatrics, Enugu State University Teaching Hospital, Enugu.

\begin{abstract}
Objectives: The objectives of the study were to determine the prevalence and socio-economic determinants of autism among children attending primary and secondary schools in South East, Nigeria.

Methods: This was a cross-sectional study that assessed the prevalence and socio-economic pattern of childhood autism among children attending primary and secondary schools in Enugu and Ebonyi states, South East Nigeria. The questionnaire was adapted from American Psychiatric Association: Diagnostic and Statistical Manual of Mental Disorders (DSM-IV-TR, 2000). The study was carried out between June and October, 2014.

The schools were selected by listing all the mixed schools in the urban and semi- urban areas by simple random sampling.

Results: A total of 721 subjects completed the questionnaire. The age of respondents ranged between 3 and 18 years, with mean age of 12.71 and standard deviation of 3.03 years. Twenty one children fulfilled the criteria for autism giving a prevalence of $2.9 \%$. There is a significant association between age in categories (fishers exact test, $\mathrm{p}=0.013$ ) and social class $(\mathrm{p}=0.033)$.

Conclusion: The prevalence of autism was 2.9\%; and the socio-economic characteristics of childhood autism in South East Nigeria are similar to those in other parts of the world.
\end{abstract}

Keywords: Childhood autism; primary and secondary schools; Nigeria.

DOI: http://dx.doi.org/10.4314/ahs.v16i4.8

Cite as: Chinawa JM, Manyike PC, Aniwada EC, Chinawa AT, Obu HA, Odetunde OI, Nwokocha ARC, Ibekwe RR. Prevalence and socioeconomic correlates of autism among children attending primary and secondary schools in south east Nigeria. Afri Health Sci 2016;16(4): 936942. http://dx.doi.org/10.4314/abs.v16i4.8

\section{Introduction}

Childhood autism is a neuro-development disorder characterized by impaired social interaction, verbal and non-

\section{Corresponding author: \\ Josephat M. Chinawa, \\ College of Medicine, Department of pediatrics, \\ University of Nigeria/ \\ University of Nigeria Teaching Hospital (UNTH), \\ Ituku- Ozalla, Enugu State, Nigeria. \\ Email: josephat.chinawa@unn.edu.ng}

African Health Sciences Vol 16 Issue 4, December, 2016 verbal communication and restricted and repetitive behaviour before the age of 36 months. ${ }^{1}$

Seven hundred and twenty one subjects who met inclusion criteria were consecutively recruited between June and October, 2014 from two secondary and two primary schools each in urban and semi-urban areas of the states. The schools were selected by listing all the mixed (boys and girls) public schools in the urban and semi-urban areas (secondary and primary separately in each state) and selecting two schools each for secondary and primary us- 
ing simple random sampling. All pupils in primary (276) and students in secondary (445) were studied giving a total of 721 respondents. Seven hundred and fifty questionnaires were administered to those that gave consent but 721 that gave consent and responded well were studied. This gave a response rate of 94\% .About 300 questionnaires were filled by respondents from Ebonyi while 421 were filled by respondents from Enugu. Of the 721 respondents; 276 parents helped their children to fill the questionnaire at home, while the remaining 445 respondents were helped by their teachers and researchers who were trained and instructed on autism questionnaire.

\section{Study procedure}

A semi-structured, self-administered questionnaire was used. Information was collected from the parents of the respondents. Older children and those whose parents were not literate had their questionnaires filled through assistance from teachers and/or researcher. Parents or respondents were asked to recall symptoms, from a list of criteria for the diagnosis of childhood autism exhibited by their children either at home or at school. Each family was assigned a socio-economic class using a recommended method, modified by Oyedeji.$^{20}$ Parents' occupations and highest level of education were assigned a score from 1 (highest) to 5 (lowest). The mean score for both parents provided a score for social class that fell within the 1-5 range. Those with a mean score $<2$ were further sub-classified into upper class, while those with a mean score $>2$ were sub-classified into a lower social class. For the occupation score, those in the upper social class included parents whose occupations included positions as senior public officers, large-scale traders, large-scale farmers, and professionals. Lower class occupations included artisans, primary school teachers, peasant farmers, laborers, and the unemployed. For the education score, those with a Ph.D., master's degree, bachelor's degree, or higher National diploma were categorized as upper class. Those with an ordinary National diploma, National certificate of education, technical education, grade II teachers' certificate, junior or senior secondary school certificate, primary school certificate, or those with no formal education were classified as lower social class. care-giving. ${ }^{20}$

\section{Ethics statement}

This was obtained from the head of the school authorities and Ministry of Education. The Ministry of Education develops the curriculum and oversees the accreditation of primary and secondary schools in Nigeria.

\section{Consent}

Informed verbal consent was sought from school teachers, parents/caregivers of potential subjects, including older students in secondary schools, before enrolling them into the study.

\section{Data analysis}

Data was analysed using the SPSS statistical package, version 17. The chi-square statistical test and T-test were used for categorical and continuous variables, respectively. The confidence interval was set at $95 \%$.

\section{Results}

Seven hundred and twenty one children filled-out the questionnaire completely. There were a total of $358 \mathrm{fe}-$ males and 363 males, with a male to female ratio of 1:1. Twenty one children fulfilled the criteria for autism giving a prevalence of $2.9 \%$. The ages of study participants ranged between 3 and 18 years-old.

Table I shows that the mean age of respondents was 12.71 with standard deviation of 3.03 years. Three hundred and sixty three (50.3\%) were males and $358(49.7 \%)$ females. The social classes of parents' showed that 459 $(63.7 \%)$ respondents belonged to the upper class, and 148 $(20.5 \%)$ respondents belonged to the lower class.

Table I: Socio-demographic characteristics of respondents

\begin{tabular}{|l|l|l|}
\hline Variable & Frequency(n=721) & Percent(100) \\
\hline Age in categories (years) & & \\
\hline$\leq 10$ & 156 & 21.6 \\
\hline $11-15$ & 433 & 60.1 \\
\hline \multicolumn{1}{|c|}{$12.72(3.03)$} & 18.3 \\
\hline Mean (SD) & \multicolumn{1}{|l|}{} \\
\hline Female & \multicolumn{1}{|c|}{$(32$} & \\
\hline Male & 358 & 49.7 \\
\hline & 363 & 50.3 \\
\hline Social Class & & \\
\hline Upper & & \\
\hline Middle & 459 & 63.7 \\
\hline Lower & 114 & 15.8 \\
\hline & 148 & 20.5 \\
\hline
\end{tabular}


Table II showed distribution of autism by socio-demographics of respondents; while none of the respondents $\leq 10$ years had autism, $15(71.4 \%)$ of those aged $11-15$ years and $132(18.3 \%)$ of those aged 16-20 had autism.
Equally 11(52.4\%) were females and 10(47.6) were males giving a male: female ratio of $1: 1$. Thirteen $(61.9 \%)$ of those with autism were in upper social class and $1(4.8 \%)$ in lower class while seven $(33.3 \%)$ in middle class. children whose fathers earn high income and mothers with low education levels had higher prevalence of autism.

Table II: Distribution of Autism by socio-demographics of respondents
\begin{tabular}{|l|l|l|}
\hline Variable & $\begin{array}{l}\text { Autism } \\
\text { N =21 }\end{array}$ & $\begin{array}{l}\text { No Autism } \\
\text { N =700 }\end{array}$ \\
\hline & $\mathbf{n}(\%)$ & n(\%) \\
\hline Age in categories (years) & & \\
\hline$\leq 10$ & $0(0.0)$ & $156(22.3)$ \\
\hline $11-15$ & $15(71.4)$ & $418(59.7)$ \\
\hline $16-20$ & $6(28.6)$ & $126(18.0)$ \\
\hline & & \\
\hline Sex & & \\
\hline Female & $11(52.4)$ & $347(49.6)$ \\
\hline Male & $10(47.6)$ & $353(50.4)$ \\
\hline Social Class & & \\
\hline Upper & $13(61.9)$ & $446(63.7)$ \\
\hline Middle & $7(33.3)$ & $107(15.3)$ \\
\hline Lower & $1(4.8)$ & $147(21.0)$ \\
\hline
\end{tabular}

Table III showed association between socio-demographics and autism. It shows a significant association between age in categories (FT, $\mathrm{p}=0.013)$ and social class $\left(\chi^{2}\right.$ $=6.829, \mathrm{p}=0.033)$. However, there were no significant association with gender $\left(\chi^{2}=0.064, \mathrm{p}=0.800\right)$.

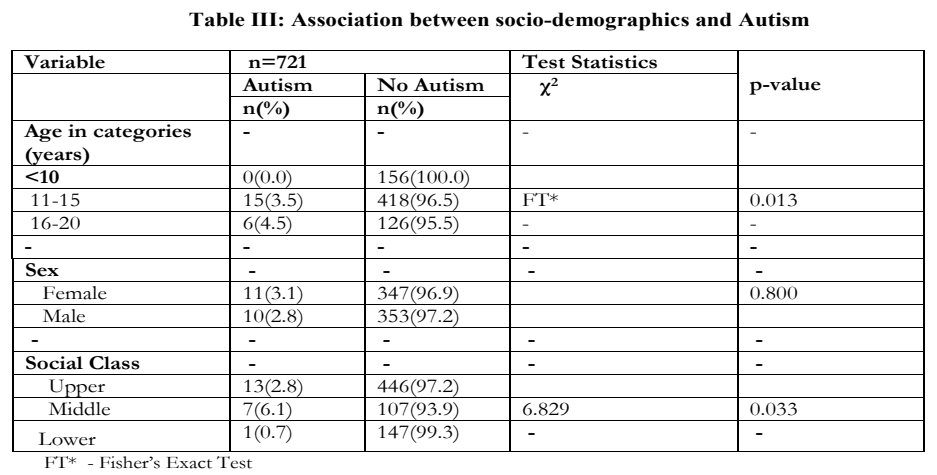

Table IV showed regression of socio-demographics on autism using odd ratio. Those whose parents belonged

to a lower social class were about 3.1 times less likely to have autism compared to those in upper and middle social class.

\begin{tabular}{|c|c|c|c|c|}
\hline \multirow{2}{*}{ Variable } & \multirow{2}{*}{ AOR } & \multirow[b]{2}{*}{ Sig. } & \multicolumn{2}{|c|}{$\begin{array}{l}95 \% \text { C.I. for adjusted odd } \\
\text { Ratio }\end{array}$} \\
\hline & & & Lower & UPPer $_{\text {Pex }}$ \\
\hline Age in categories (years) & - & - & - & - \\
\hline$\leq 10$ & - & - & - & - \\
\hline $11-15$ & $\mathrm{NA}$ & NA & $\mathrm{NA}$ & $\mathrm{NA}$ \\
\hline $16-20$ & - & - & - & - \\
\hline- & - & - & - & - \\
\hline Sex & - & - & - & - \\
\hline Female (R) & - & - & - & - \\
\hline Male & 0.812 & 0.642 & 0.337 & 1.956 \\
\hline- & - & - & - & - \\
\hline Social Class & - & - & - & - \\
\hline Upper(R) & & 0.274 & & \\
\hline Middle & 2.692 & 0.043 & 1.033 & 7.019 \\
\hline Lower & 0.325 & 0.281 & 0.042 & 2.515 \\
\hline
\end{tabular}

Table $\mathrm{V}$ shows the mean positive values for diagnosis in both those with or without Autism. There was a sig- nificant difference between the mean symptom values for those that have Autism and those without Autism $p$ $=0.000$. 
Table V: Mean positive values for diagnosis in both those with or without Autism

\begin{tabular}{|l|l|l|l|l|}
\hline Variable & $\begin{array}{l}\text { Autism } \\
\mathbf{N}=\mathbf{2 1}\end{array}$ & $\begin{array}{l}\text { No Autism } \\
\mathbf{N}=\mathbf{7 0 0}\end{array}$ & $\begin{array}{l}\text { Test statistic } \\
\mathbf{t} \text { test }\end{array}$ & $\mathbf{P}$ value \\
\hline Using percentage (\%) & & & & \\
\hline Social life & & & & \\
\hline Communication & $63.90 \pm 2.75$ & $18.16 \pm 0.43$ & 28.48 & 0.000 \\
\hline Patterns of behavior & & & & \\
\hline & & & & \\
\hline
\end{tabular}

\section{Discussion}

From this study, we noted that the prevalence of childhood autism was $2.9 \%$. Several reviews of the literature have reported highly variable prevalence rates for autism Worldwide, ranging from $1 \%$ to almost 14.7 per 1,000. care-giving $^{21}$ Although the causes of the variability in autism prevalence Worldwide are unknown, geographic and demographic factors have been implicated. ${ }^{22}$ The fact that geographical location may influence the epidemiology of childhood autism persists despite findings that culture and geographic location may have little or no influence on the epidemiology of autism Worldwide. ${ }^{23}$

The fact that a percentage of the parents who are not literate, in this study, may have some bias due to poor understanding of the questionnaire even when it is interpreted in their own dialect may have affected the prevalence rate in this study. A questionnaire which is translated into the dialect of these parents could have improved the actual prevalence rate of autism in this setting. The issue of recall bias could also explain the variation of prevalence when compared with those from different region. Furthermore, a locally developed questionnaire may be important in future studies on autism to reduce ethno-cultural bias. For instance, Kakooza ${ }^{24}$ et al, in Uganda, developed a 23-question screener on autism. This questionnaire is very important in household screening and is tailored to Ugandan needs. The use of this questionnaire in other African countries would be worthwhile.

In the present study, we noted no significant gender difference in the pattern of childhood autism. This is different from the results of most studies where a male preponderance was noted. ${ }^{23,25}$ It has been noted that autism is usually under diagnosed in females. It has been stipulated that autism characteristics in females depend strongly on their level of intelligence. ${ }^{26}$ "On one end, they tend to have more social communication impairment and lower cognitive ability" than boys who have the disorder, "On the other end, they have fewer restricted interests."These differences may make it difficult for parents, teachers and doctors to recognize the signs of autism in girls. ${ }^{26}$ This is especially true because autism has traditionally been thought of as a male problem. In fact, researchers are now beginning to question the degree of this gender disparity. ${ }^{26}$

It is noted that for most severe cases of autism, the ratio of autism in boys and girls is nearly $1: 1{ }^{27}$ This has led to speculation that girls with autism have a few symptoms that differ from boys and thus are under diagnosed. ${ }^{27}$ The original description of autism was based on case studies of males, and the underlying reason for some of the behaviors might manifest differently in males and females. Females with autism might not come to the notice of parents or educators because those few behaviors in which they differ from males might mask the diagnosis. ${ }^{27}$

The trend of lower sex/gender ratio and dissociation may mean that recent studies have been more successful in identifying higher-functioning females, who may have been missed previously, particularly in clinic- or schoolbased samplings that are susceptible to bias. care-giving ${ }^{28}$

The reason why we found equivalent prevalence in both genders may be because of a large sample size used in the study.

It is pertinent to note that majority of our subjects who met the diagnostic criteria of autism were mainly within the age of 11-15 years. Early detection of children with autism is crucial but often delayed until school age. care-giving ${ }^{29}$. Few studies have identified factors that may delay diagnosis ranging from the fact that many physicians have limited knowledge of the presentation, prognosis, and treatment of this disorder to lack of awareness. Other factors could be due to level of education of the mother. This is corroborated in our study where majority of the mothers of children with autism have low level of education.

We noted that children whose fathers earn high income and mothers with low education levels have higher prevalence of autism. Early studies identified consistent associations between parental education and autism; however more current studies noted little or no association beAfrican Health Sciences Vol 16 Issue 4, December, 2016 
tween parental education, income, or wealth and autism. care-giving $^{30}$

In our study, we had more children with autism presenting mainly with communication than social and behavioral problems and this was significant. This is similar to studies where communication difficulties have been implicated. care-giving ${ }^{31,32}$ Commonly, the first sign that alerts a pediatric clinician to a child with possible autism is a deficit in communication, manifested by a delay in or abnormal use of language, at approximate ages of 18 to 24 months. It is a known fact that a child with autism may initially be mute, have a significant delay in language acquisition, or have a regression in language. ${ }^{32}$ Often, but not always, children with autism will have delays in developing spoken language. Some individuals with autism remain non-verbal throughout their life. ${ }^{32}$

When we correlated socio-economic class and prevalence of autism, we noted a higher prevalence among children whose parents are of high socioeconomic class. This finding is in keeping with that of Maureen et al who noted a high prevalence of autism among parents from a high socio-economic class.care-giving ${ }^{33}$

Autism has been positively associated with high socioeconomic status (SES) in at least eight epidemiological studies from different populations and in different ethnic backgrounds. ${ }^{12,13,34,35}$, while two Scandinavian studies did not find that association. care-giving ${ }^{34}$ Although the causal basis for these associations with autism are unclear, many autism studies have suggested that they may be related to access to health resources, in the context of higher income and/ or education, influencing increasing autism diagnosis. ${ }^{35}$ Other explanations for geographical clustering of autism have been suggested including clustering due to information related occupations as well as rainfall.$^{35}$

These findings emphasize the importance of accessible diagnostic resources and services for all children with Autism, especially those children from homes with fewer economic resources. ${ }^{28}$

\section{Strength and limitation}

We did not do any screening and follow up on those with probable autism. A cohort study will be necessary to follow up these children with autism. The issue of recall bias could also affect the prevalence rate in this study. The strength of this article lies in the fact that it is one of the very few works on autism in this part of the country.

African Health Sciences Vol 16 Issue 4, December, 2016

\section{Conclusion}

We conclude that the prevalence and socio-economic characteristics of childhood autism in this South East Nigeria was similar to that in other parts of the World, and there is need for additional studies in this sub-region. This is because childhood autism is one of the emerging mental health problems and a neglected health issue in Africa.

\section{Competing interests}

The authors declare no competing interests.

\section{Authors' contributions}

Dr. JMC had primary responsibility for protocol development, patient screening, enrolment, outcome assessment, preliminary data analysis, and writing of the manuscript. Dr. PCM and JMC also supervised the design and execution of the study, and performed the final data analyses. Drs. HAO, CAT, JMV, PCM, ARN and AE participated in the development of the protocol and analytical framework for the study, and contributed to writing of the manuscript. Dr AE did all the statistical analysis.

\section{References}

1. Chakrabarti S, Fombonne E. Pervasive developmental disorders in preschool children: confirmation of high prevalence. Am J Psychiatry. 2005; 162:1133-1141; DOI: 10.1176/appi.ajp.162.6.1133 PubMed

2. Fombonne E. Epidemiology of autistic disorder and other pervasive developmental disorders. J Clin Psychiatry. 2005; 66: 3-8; DOI;http://www.ncbi.nlm.nih.gov/ pubmed/16401144

3. Kim YS, Leventhal BL, Koh YJ, Fombonne E, Laska E, Lim EC et al. Prevalence of autism spectrum disorders in a total population sample. Am J Psychiatry. 2011; 168:904-12; DOI: 10.1192/bjp.bp.111.104703

4. Lavelle TA, Weinstein MC, Newhouse JP, Munir K, Kuhlthau KA,Prosser LA. Economic burden of childhood autism spectrum disorders. Pediatrics 2014; 133: 5209; DOI: 10.1542/peds.2013-0763.

5. Bakare MO, Ebigbo PO, Ubochi VN. Prevalence of autism spectrum disorder among Nigerian children with intellectual disability: a stopgap assessment. J Health Care Poor Underserved. 2012; 23:513-8; DOI: $10.1111 /$ dmcn. 12150

6. John WH, Korrie A. The Clinician's Guide to Autism. Pediatrics in Review 2014; 35: 62 -78; DOI:10.1542/pir.352-62

7. Rice Catherine PhD. Prevalence of autism spec- 
trum disorders-Autism and Developmental Disabilities Monitoring Network, United States, 2006. MMWR Surveill Summ. 2009;58:1-20; DOI: 10.1371/journal. pone. 0124120

8. Honda H, Shimizu Y, Rutter M. No effect of MMR withdrawal on the incidence of autism: a total population study. J Child Psychol Psychiatry. 2005;46:572-99; DOI: 10.1111/j.1469-7610.2005.01425.x

9. Senecky Y, Chodick G, Diamond G, Lobel D, Drachman R, Inbar D.Time trends in reported autistic spectrum disorders in Israel, 1972-2004. Isr Med Assoc J. 2009;11:30-3;DOI;http://www.ncbi.nlm.nih.gov/ pubmed/19344009

10. Al-Salehi SM, Al-Hifthy EH, Ghaziuddin M. Autism in Saudi Arabia: presentation, clinical correlates and comorbidity. Transcult Psychiatry 2009; 46: 340-7 ; DOI: 10.1177/1363461509105823

11. Wong VCN, Hui SLH. Epidemiological study of autism spectrum disorder in China. J Child Neurol 2008;23:67-72; DOI: 10.1177/0883073807308702

12. Thomas P, Zahorodny W, Peng B, Kim S, Jani N, Halperin $\mathrm{W}$ et al. The association of autism diagnosis with socioeconomic status. Autism 2012; 16:201-13; DOI: 10.1177/1362361311413397

13. Ariane VS, Zuleyha C, Martin K, David SM .Costs of Autism Spectrum Disorders in the United Kingdom and the United States. JAMAPediatr. 2014; 168:721-728; DOI:10.1001/jamapediatrics.2014.210

14. King MD, Bearman PS. Socioeconomic status and the increased prevalence of autism in California. Am Sociol Rev 2011; 76:320-346; DOI: 10.1177/0003122411399389. PubMed

15.Wing L. Childhood autism and social class: a question of selection? Br J Psychiatry. 1980; 137:410-7; Pediatrics in Review 2014; 35; 62; DOI:10.1542/pir.35-2-62)

16. Pierce K, Muller RA, Ambrose J, Allen G, Courchesne E. Face processing occurs outside the fusiform 'face area' in autism: evidence from functional MRI. Brain 2001; 124:2059-2073; DOI: http://dx.doi.org/10.1093/ brain/124.10.2059 2059-2073

17. Rajendran G, Mitchell P. Cognitive Theories of Autism. Dev Rev. 2007; 27:224-260; DOI:10.1016/j. dr.2007.02.001

18. Baron-Cohen S, Ring HA, Bullmore ET, Wheelwright S, Ashwin C, Williams SC. The amygdala theory of autism. Neurosci Biobehav Rev. 2000; 24:355-364; DOI, 10.1016/S0149-7634(00)00011-7

19. American Psychiatric Association: Diagnostic and Statistical Manual of Mental Disorders, 4th ed., text revision
(DSM-IV-TR, 2000). Arlington, VA, American Psychiatric Association,2000; DOI,http://dsm.psychiatryonline. org/doi/book...76/appi.books.978089042559

20. Oyedeji GA. Socio- economic and cultural background of hospitalized children in llesha. Nigeria Journal of Paediatrics. 1985; 12:111-7; DOI, http://www.njpaediatrics.com/1985/v12n4/...ldren\%2520in\%2520Ilesha.pd 21. Irva H, Lora D. The Rise in Autism and the Role of Age at Diagnosis. Epidemiology 2009; 20: 84-90; DOI: 10.1097/EDE.0b013e3181902d15

22. Silverman C. Fieldwork on another planet: social science perspectives on the autism spectrum". Biosocieties 2008; 3: 325-41; DOI:10.1017/S1745855208006236

23. Tina TD, Lynn KW, Richard RS, Festus EO, Bob A. Multicultural Issues in Autism. Journal of Autism and Developmental Disorders 2004; 34:211-222; DOI: 10.1023/B:JADD.0000022611.80478.73

24. Kakooza-Mwesige A, Ssebyala K, Karamagi C, Kiguli S, Smith K, Anderson MC et al.. Adaptation of the "Ten Questions" to Screen for Autism and other Neurodevelopmental Disorders in Uganda. The International Journal of Research and Practice 2014; 18447-457 ; DOI: 10.1177/1362361313475848

25. Lenoir P, Bodier C, Desombre H, Malvy J, Abert B, Ould Taleb $\mathrm{M}$ et al. Prevalence of pervasive developmental disorders. A review. Encephale 2009; 35:36-42; DOI: 10.1016/j.encep.2007.12.011

26. Autism characteristics differ by gender. Obtainable from http://sfari.org/news-and-opinion/news/2...fferby-gender-studies-fin. Assessed on 4/11/2014

27. Does autism affect more females or males - Obtainable from www.answers.com > Categories > Health > Conditions and Diseases. Assessed on 31/08/2015.

28. Hiller R.M., Young R.L., Weber N. Sex Differences in autism spectrum disorder based on DSM-5 criteria: evidence from clinician and teacher reporting. $J$ Abnorm Child Psychol 2014; 42:1381-1393; DOI: 10.1007/s10802014- 9881-x

29.David SM, ScD MM, Novak MA, Cynthia DZ . Factors Associated With Age of Diagnosis Among Children With Autism Spectrum Disorders. ; DOI:http://pediatrics.aappublications.org/content/116/6/1480

30. Larsson H, William E, Kreesten M, Mogens V, Anne O, Esben A et al. Risk Factors for Autism: Perinatal Factors, Parental Psychiatric History, and Socioeconomic Status. American Journal of Epidemiology 2005; 161:916-25; DOI: 10.1093/aje/ kwi123

31. Fombonne E. Epidemiology of autistic disorder and other pervasive developmental disorders. J Clin PsychiaAfrican Health Sciences Vol 16 Issue 4, December, 2016 
try 2005; 66:3-8. DOI;http://www.ncbi.nlm.nih.gov/ pubmed/16401144

32. John WH, Korrie A. The Clinician's Guide to Autism. Pediatrics in Review 2014; 35; 62; DOI:10.1542/pir.35-262)

33. Maenner MJ, Arneson CL, Durkin MS . Socioeconomic disparity in the prevalence of autism spectrum disor- der in Winsconsin. WMJ 2009; 108:253-5; DOI:10.1371/ journal.pone.0011551

34.King MD, Bearman PS. Socioeconomic Status and the Increased Prevalence of Autism in California. Am Sociol Rev 2011; 76:320-346; DOI ;1177/0003122411399389. 35. Becker KG. Autism, Autoimmune Disease and Socioeconomic Status. Autism 2012; 2:104; DOI: 10.4172/21657890.1000104 